\title{
Hypothalamic hypogonadism in hemochromatosis: A case report
}

\author{
Igor Matwijiw, MD, FRCP(C), Gerald D. IlifFe, MD, FRCP(C), AdI E. Mehta, MD, FRCP(C), \\ ChARLES FAIMAN, MD, FRCP(C)
}

\begin{abstract}
A 42-year-old man developed hypogonadotropic hypogonadism due to primary hemochromatosis. Endocrine evaluation indicated a hypothalamic defect in the control of gonadotropin secretion. Although cirrhosis was present on liver biopsy, other major features of the hemochromatosis syndrome were not manifest. Patients with hemochromatosis are now being diagnosed at earlier stages of disease. Clinicians should be alert to possible early development of hypothalamopituitary dysfunction and should be prepared to perform detailed endocrinological investigations in such patients. Can J Gastroenterol 1988; 2(1): 31-34
\end{abstract}

Key Words: Hemochromatosis, Hypogonadism, Hypothalamus, Pituitary gonadotropins
Drimary idiopathic hemochromatosis is a slowly developing hereditary metabolic disorder characterized by excessive absorption of iron from the gut and its deposition within the parenchymal cells of the body. The liver, pancreas and skin as well as the heart, joints and the anterior pituitary gland appear to be particularly affected (1-3). Typically, patients are middleaged men who present with unexplained cirrhosis accompanied by diabetes mellitus and abnormally pigmented skin $(1,3)$. Hypogonadotropic hypogonadism occurs in up to $64 \%$ of all individuals with advanced disease $(2,3)$. Primary testicular dysfunction, although less frequent, also may occur $(4,5)$.

The ready availability of laboratory techniques such as assays for serum iron, total iron binding capacity and ferritin, HLA typing and liver biopsy, has made it possible to diagnose this
Departments of Medicine and Physiology, University of Manitoba and the Endocrine-

Metabolic Laboratory, Health Sciences Centre, Winnipeg

Correspondence and reprints: Dr I. Matwijiw, G449 Health Sciences Centre, 700 William

Avenue, Winnipeg, Manitoba R3E 023

Received for publication August 14, 1987. Accepted October 28, 1987 disease in its early stages (5). Homozygotes can be diagnosed when there is little or no clinical evidence of disease $(4,6)$. It is, therefore, likely that in the future many cases will be diagnosed before the classic manifestations of the syndrome have developed.

Present understanding of disease pathogenesis in advanced hemochromatosis may not be applicable to the syndrome in its earliest stages. A case of a 42-year-old man in whom a diagnosis of hemochromatosis was made during the investigation of acquired hypogonadotropic hypogonadism is presented. Endocrine investigations revealed evidence of hypothalamic dysfunction rather than the typical primary gonadotrope cell failure seen in advanced disease.

\section{CASE PRESENTATION}

A 42-year-old white man was referred to the Reproductive Endocrine Clinic at the University of Manitoba because of decreased libido and impotence which had developed over an 18 month period. He was subsequently referred to the Section of Gastroenterology for investigation of elevated liver 
enzymes. Prior to this time he had been in good health. Systematic inquiry relevant to his liver disease was negative; in particular, there had been no previous history of jaundice, drug or alcohol abuse, blood transfusions, pruritus, skin or eye complaints. There had been no foreign travel. There was no family history of liver disease or diabetes mellitus. He had previously fathered two children.

Physical examination showed him to be $188 \mathrm{~cm}$ tall, weight $75 \mathrm{~kg}$. There were no peripheral stigmata of liver disease. In particular, there were no liver palms, spider angiomata or gynecomastia. Liver span was $12 \mathrm{~cm}$ in the mid-clavicular line and increased in consistency. He had normal body proportions and body hair. Visual fields and fundi were normal as was sense of smell. His penis was normal. The right testis was of normal size (5.0 $\times 3.0 \mathrm{~cm}$ ) and consistency but the left testis was $2 \mathrm{~cm}$ in length and soft, probably related to surgery as a child for an undescended testis. The prostate gland was small.

Investigątions revealed elevated serum aspartate transaminase at $79 \mathrm{iu} /$ L (normal, less than 50), serum alanine transaminase at $81 \mathrm{iu} / \mathrm{L}$ (normal, 10 to $40)$ and serum alkaline phosphatase at $158 \mathrm{iu} / \mathrm{L}$ (normal, 30 to 125 ). Serum bilirubin and albumin levels were normal as were serum ceruloplasmin and $\alpha_{1}$-antitrypsin levels. Serology for hepatitis $\mathrm{A}$ and $\mathrm{B}$, antinuclear and antimitochondrial antibodies was negative. However, his serum iron was 38 mmol/L (normal, 8 to 24 ), total iron binding capacity $39 \mathrm{mmol} / \mathrm{L}$ (normal, 45 to 72 ) and serum ferritin $2700 \mu \mathrm{g} / \mathrm{L}$ (normal, 20 to 200). A liver/spleen scan showed hepatosplenomegaly with diminished activity throughout the liver consistent with diffuse parenchymal disease as well as moderate enlargement of the spleen with increased activity.

A liver biopsy showed irregular bands of fibrosis with well defined nodules consistent with a diagnosis of cirrhosis without any active inflammation. Kupffer cells, liver parenchyma and bile duct epithelium showed heavy iron deposition; the overall picture was

TABLE 1

Results of anterior pituitary function tests

\begin{tabular}{lrr}
\hline Serum hormone & Basal (normal) & $\begin{array}{c}\text { Peak stimulated } \\
\text { (normal) }\end{array}$ \\
\hline Testosterone $(\mathrm{nmol} / \mathrm{L})$ & $5.2(8-35)$ & - \\
$\quad$ Mean of 10 samples & $2.3-7.5$ & - \\
$\quad$ Range & $1.5(2.8-11.7)$ & - \\
Free testosterone indext & $50(<180)$ & $290(1.3-3 \times$ basal) \\
Estradiol $(\mathrm{pmol} / \mathrm{L})$ & $210(80-300)$ & $100(2-6 \times$ basal) \\
$\mathrm{FSH}(\mu \mathrm{g} / \mathrm{L})$ & $40(30-110)$ & $19(2-6 \times$ basal) \\
$\mathrm{LH}(\mu \mathrm{g} / \mathrm{L})$ & $5(<15)$ & $18(>5)$ \\
Prolactin $(\mu \mathrm{g} / \mathrm{L})$ & $1.7(<5)$ & $1060(>550)$ \\
Growth hormone $(\mu \mathrm{g} / \mathrm{L})$ & $630(150-700)$ & - \\
Cortisol $(\mathrm{nmol} / \mathrm{L})$ & $<2(<6)$ & $13(6-30)$ \\
TSH $(\mathrm{mU} / \mathrm{L})$ & $116(50-140)$ & - \\
Thyroxine $(\mathrm{nmol} / \mathrm{L})$ & &
\end{tabular}

- Following combined intravenous bolus injection of gonadotropin-releasing hormone (Factrel; Ayerst) $100 \mu \mathrm{g}$ thyrotropin-releasing hormone (Relefact; Hoechst) $400 \mu \mathrm{g}$ and crystalline insulin 8 units $10.1 \mathrm{U} / \mathrm{kg}$ )

†Estimate of nonprotein-bound testosterone present in serum: calculated by multiplying the percentage free testosterone by the total testosterone concentration (7)

FSH Follicle stimulating hormone; LH Luteinizing hormone; TSH Thyroid stimulating hormone

consistent with a diagnosis of hemochromatosis.

Results of endocrine investigation are shown in Table 1 . Serum testosterone levels were repeatedly below normal. The free testosterone index was also subnormal (7). Basal levels of luteinizing hormone ( $\mathrm{LH}$ ) and follicle stimulating hormone (FSH) were normal as was pituitary gonadotropin reserve when tested with synthetic gonadotropin releasing hormone $(\mathrm{G} R \mathrm{RH})$. Provocative tests of anterior pituitary function were within normal limits. The patient was biochemically euthyroid. An oral glucose tolerance test was within normal limits according to the criteria of the National Diabetes Data Group (8). A high resolution computerized tomographic scan of the pituitary fossa was normal.

The patient was started on a program of phlebotomy and testosterone enanthate injections, $200 \mathrm{mg}$ intramuscularly every three weeks, with marked improvement in both his libido and potency.

\section{DISCUSSION}

This report represents the first description of hypothalamic hypogonadotropism in primary (genetic) hemochromatosis. The diagnosis of hemochromatosis was based on a history of minimal alcohol ingestion, the findings of elevated hepatic enzymes and increased serum iron and ferritin concentrations. It was confirmed by pathologic findings consistent with this disorder on a liver biopsy specimen. The absence of portal hypertension, diabetes mellitus or cardiac abnormalities suggests that the diagnosis was made in the early stages of disease in this patient.

The presence of inappropriately normal serum gonadotropin levels in a setting of persistently low serum testosterone concentrations and a unilateral atrophic testis, indicates the presence of hypogonadotropism. Even though normal pituitary gonadotropin reserve has been demonstrated in patients with advanced primary and secondary hemochromatosis, typically, when basal serum testosterone concentrations are subnormal, as in this case, the pituitary is unresponsive to a single dose of $\mathrm{GnRH}(9,10)$. Pituitary unresponsiveness to an acute $\mathrm{GnRH}$ challenge cannot reliably differentiate a primary gonadotrope cell abnormality from a hypothalamic defect (11). However, a brisk response, as seen in this case, points towards the latter (12). Taken together, these findings suggest that, in this patient, the predominant defect in the control of gonadotropin secretion was at the hypothalamic, rather than the pituitary level.

In the past, pituitary dysfunction has been well documented in both primary and secondary hemochromatosis by both the anatomic demonstration 
of iron deposition within gonadotrope cells (13) and the absence of pituitary gonadotropin reserve following challenge with repeated doses of $\mathrm{GnRH}$ $(14,15)$. These studies were performed in patients with advanced disease, however, and primary gonadotrope cell failure in advanced hemochromatosis does not preclude the presence of hypothalamic dysfunction in the earlier stages of this disorder. Indeed, past studies performed using single dose, acute $\mathrm{GnRH}$ challenges may have overlooked individuals who actually had hypothalamic disease $(9,10)$.

Data on hypothalamo-pituitarygonadal axis function in the early stages of hemochromatosis are scanty. Edwards and colleagues (4) documented five cases of hypogonadotropism in a series of 21 patients diagnosed in the earliest stages of disease by pedigree analysis. However, GnRH challenge testing was not performed. In a similar, asymptomatic, group with early disease, Feller and co-workers (6) reported the presence of normal pituitary gonadotropin reserve to an acute $\mathrm{GnRH}$ challenge. However, only five individuals without clinical evidence of hypogonadism were evaluated. Therefore, the prevalence of hypothalamic dysfunction in the early stages of primary hemochromatosis is not known.

The cause of hypothalamic dysfunction in hemochromatosis is unknown. The authors are unaware of any reports of hypothalamic pathology in

\section{REFERENCES}

1. Finch SC, Finch CA. Idiopathic hemochromatosis, an iron storage disease. Medicine (Baltimore) 1955; 34: $381-430$.

2.Lamon JM, Marynick SP, Rosenblatt $\mathrm{R}$, Donnelly S. Idiopathic hemochromatosis in a young female. A case study and a review of the syndrome in young people. Gastroenterology 1979; 76: 178-83.

3. Milder MS, Cool JD, Stray S, Finch CA. Idiopathic hemochromatosis, an interim report. Medicine (Baltimore) 1980; 59: 34-49.

4. Edwards CQ, Cartwright GE, Skolnick MH, Amos DB.

Homozygosity for hemochromatosis: clinical manifestations. Ann Int Med this disorder. Data from in vivo studies on hypothalamic iron deposition using advanced techniques such as nuclear magnetic resonance imaging are as yet unavailable $(16,17)$. Regardless of the mechanism of hypothalamic injury, the previous report of combined $\mathrm{GnRH}$ and thyrotropin-releasing hormone deficiency in a patient with secondary hemochromatosis (18) suggests that a number of hypothalamic hormones which regulate pituitary secretion may be affected.

Abnormal hypothalamic control of gonadotropin secretion has also been delineated in individuals with advanced alcoholic liver disease both by GnRH testing (19) and by analysis of pulsatile LH secretion (20). These patients exhibited findings of advanced liver disease such as portal hypertension, gynecomastia and increased serum estrogen levels. The absence of any of these findings in the present patient suggests that hepatic decompensation was not a major factor in the development of his hypogonadotropism, despite the presence of cirrhosis on liver biopsy.

It is likely that cirrhosis per se plays a minor role in the development of the hypogonadotropism seen in iron overload states. For instance, abnormally increased serum sex hormone binding globulin concentrations and peripheral aromatization of androgens to estrogens, typical of alcoholic cirrhosis, are not usually seen in hemochromatosis (21). In a recent large ret-

1980; 93: 519-25.

5. Powell LW, Basset ML, Halliday JW. Hemochromatosis: 1980 update. Gastroenterology 1980; 78: 371-4.

6. Feller ER, Pont A, Wands JR, et al. Familial hemochromatosis: physiologic studies in the precirrhotic stage of the disease. N Engl J Med 1977; 296: 1422-6.

7.Stearns EL, MacDonnell JA, Kaufman BJ, et al. Declining testicular function with age: hormonal and clinical correlates. Am J Med 1974; 57:761-6.

8. National Diabetes Data Group. Classification and diagnosis of diabetes mellitus and other categories of glucose intolerance. Diabetes 1979; 28:1039-57.

9. Bezwoda WR, Bothwell TH, Van Der rospective study of patients with hemochromatosis (22), the prevalence of impotence was slightly greater in cirrhotics than in noncirrhotics. How ever, it is unlikely that this complication is causally related to the presence of cirrhosis as, in that study, the percentage of patients with diabetes mellitus and ethanol abuse was significantly greater in patients with severe liver disease. These latter two factors could have independently increased the prevalence of impotence in this group, especially because specific causes of erectile dysfunction such as hypogonadism, neuropathy and vascular disease were not detailed. Of interest, among the women in that study, the frequency of amenorrhea was similar in both the cirrhotic and noncirrhotic groups, suggesting that in iron overload states the prevalence of abnormal gonadotropin secretion is similar in those with and without severe liver disease.

Once established, hypogonadotropism in iron overload states is considered permanent (17). However, in view of the reports of reversal of hypogonadotropism with phlebotomy $(23,24)$ and of the diagnosis of this disease in its earliest stages with such techniques as HLA typing (4-6), prospective study of the function of the hypothalamo-pituitary-gonadal axis, and indeed all aspects of hypothalamopituitary function, in early hemochromatosis will be necessary to help judge the effectiveness of therapy.

Walt LA, Kronheim S, Pimstone BL. An investigation into gonadal dysfunction in patients with idiopathic haemochromatosis. Clin Endocrinol (Oxford) 1977; 6: 377-85.

10. Charbonnel B, Chupin M, Legrand A, Guillon J. Pituitary function in idiopathic hemochromatosis: hormonal study in 36 male patients. Acta Endocrinol 1981; 98: 178-83.

11. Spitz IM, Diamant Y, Rosen E, et al. Isolated gonadotropin deficiency: a heterogeneous syndrome. $\mathrm{N}$ Engl J Med 1974; 290: 10-5.

12. Hashimoto T, Kiyoshi M, Izumi K, Kumahara Y. Isolated gonadotropin deficiency with response to luteinizing hormone releasing hormone. $\mathrm{N}$ Engl J 
Med 1972; 287: 1059-62.

13. Bergeron C, Kovacs K. Pituitary siderosis: a histologic immunocytologic and ultrastructural study. Am J Pathol 1978; 93: 295-306.

14. Kletzky OA, Costin G, Marrs RP, Bernstein G, March CM, Mishell DR. Gonadotropin insufficiency in patients with thalassemia major. J Clin Endocrinol Metab 1979; 48: 901-5.

15. Snyder PJ, Rudenstein RS, Gardner DF, Rothman JG. Repetitive infusion of gonadotropin-releasing hormone distinguishes hypothalamic from pituitary hypogonadism. J Clin Endocrinol Metab 1979; 48: 864-8.

16. Valberg LS, Ghent CN. Diagnosis and management of hereditary hemochromatosis. Ann Rev Med 1985; 36:27-37. 17. Lufkin EG, Baldus WP, Bergstrath EJ,
Kao PC. Influence of phlebotomy treatment on abnormal hypothalamicpituitary function in genetic hemochromatosis. Mayo Clin Proc 1987; 62: 473-9.

18. Williams TC, Frohman LA. Hypothalamic dysfunction associated with hemochromatosis. Ann Int Med 1985; 103: 550-1.

19. Van Thiel DH, Lester R. Further evidence for hypothalamic-pituitary dysfunction in alcoholic men. Alcoholism Clin Exp Res 1978; 2: 265-70.

20. Bannister P, Handley T, Chapman C, Losowsky MS. Hypogonadism in chronic liver disease: impaired release of luteinizing hormone. Br Med J 1986; 293: 1191-3.

21. Kley HK, Niederau C, Stremmel W, Lax R, Strohmeyer G, Kruskemper
HL. Conversion of androgens to estrogens in idiopathic hemochromatosis: Comparison with alcoholic liver cirrhosis. J Clin Endocrinol Metab 1985; 61: 1-6.

22. Niederau C, Fischer R, Sonnenberg A, Stremmel W, Trampisch HJ, Strohmeyer G. Survival and causes of death in cirrhotic and noncirrhotic patients with primary hemochromatosis. N Engl J Med 1985; 313: 1256-62.

23. Kelly T, Edwards CQ, Meikle AW, Kushner JP. Hypogonadism in hemochromatosis: reversal with iron depletion. Ann Int Med 1984; 101: 629-32.

24. Siemons LJ, Mahler C. Hypogonadotropic hypogonadism in hemochroma. tosis: Recovery of reproductive function after iron depletion. J Clin Endocrinol Metab 1987; 65: 585-7.

\section{Clinical quiz - Answers}

\section{PANCREAS}

1. Clinical or laboratory features at admission or during first 48 h of hospitalization which correlate with severe or complicated course and increased risk of mortality in acute ethânol-associated pancreatitis

At admission

Older than 55 years

White blood cell count more than $16,000 / \mathrm{mm}^{3}$

Blood glucose more than $200 \mathrm{mg} / \mathrm{dL}$ (no history of prior hyperglycemia)

Serum lactate dehydrogenase more than $350 \mathrm{iu} / \mathrm{L}$

Aspartate aminotransferase levels above $250 \mathrm{iu} / \mathrm{L}$

During initial $48 \mathrm{~h}$

Hematocrit falls more than $10 \%$

Blood urea nitrogen rises more than $5 \mathrm{mg} / \mathrm{dL}$

Arterial $\mathrm{pO}_{2}$ less than $60 \mathrm{mmHg}$

Base deficit greater than $4 \mathrm{mEq} / \mathrm{L}$

Serum calcium less than $8 \mathrm{mg} / \mathrm{dL}$

Estimated fluid sequestration

\section{Complications of cystic fibrosis}

Gut

Meconium ileus - constipation

Rectal prolapse - obstruction

Intussusception

Liver

Gallstones

Focal biliary cirrhosis

Fatty liver

Cirrhosis and portal hypertension

Cholecystitis

Pancreas

Pancreatic atrophy

Diabetes

Pancreatitits

\section{STOMACH}

1. Phases of gastric acid secretion and probable mechanisms of control

\begin{tabular}{ll}
\hline Phase & Control mechanism \\
\hline Spontaneous or basal & $\begin{array}{c}\text { Vagus } \\
\text { gastrin } \\
\text { Cephalic }\end{array}$ \\
& Vagus \\
& stimulation of parietal cells \\
Gastric & Vagus \\
& stimulation of parietal cells \\
& stimulation of gastrin-secreting cells \\
& Vasovagal reflexes \\
& distension \\
& Local reflexes \\
& distension \\
chemical (protein, amino acids) \\
Intestinal gastrin release \\
Distension of jejunum \\
Intestinal chyme
\end{tabular}

2. Causes of hypergastrinemia

Hypersecretion of acid

Gastrinoma

Antral G cell hyperplasia

Retained gastric antrum

Massive small bowel resection

Variable acid secretion

Chronic renal failure

Pheochromocytoma

Hyperthyroidism

Hyposecretion of acid

Pernicious anemia

Atrophic gastritis

Gastric carcinoma

After vagotomy and pyloroplasty 


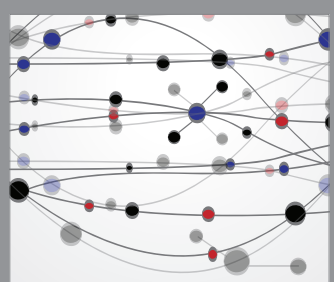

The Scientific World Journal
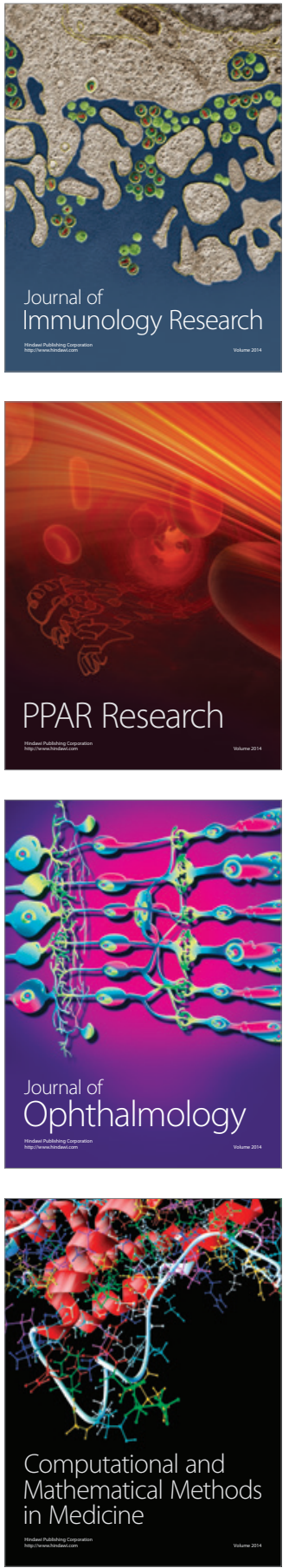

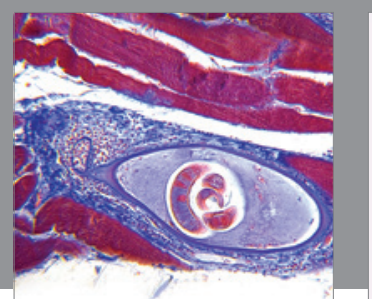

Gastroenterology Research and Practice

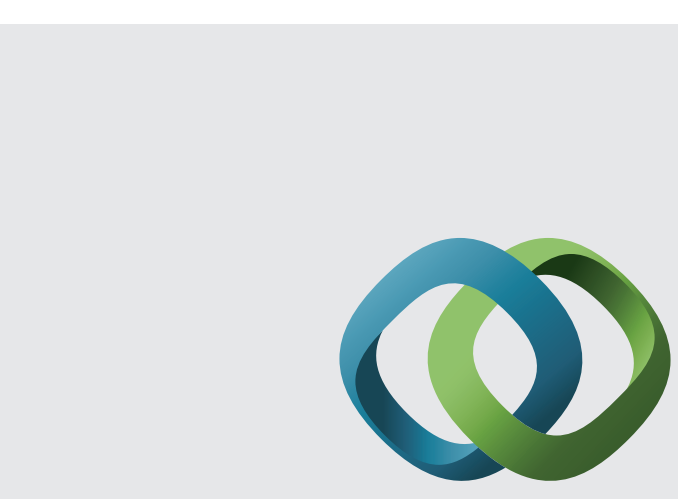

\section{Hindawi}

Submit your manuscripts at

http://www.hindawi.com
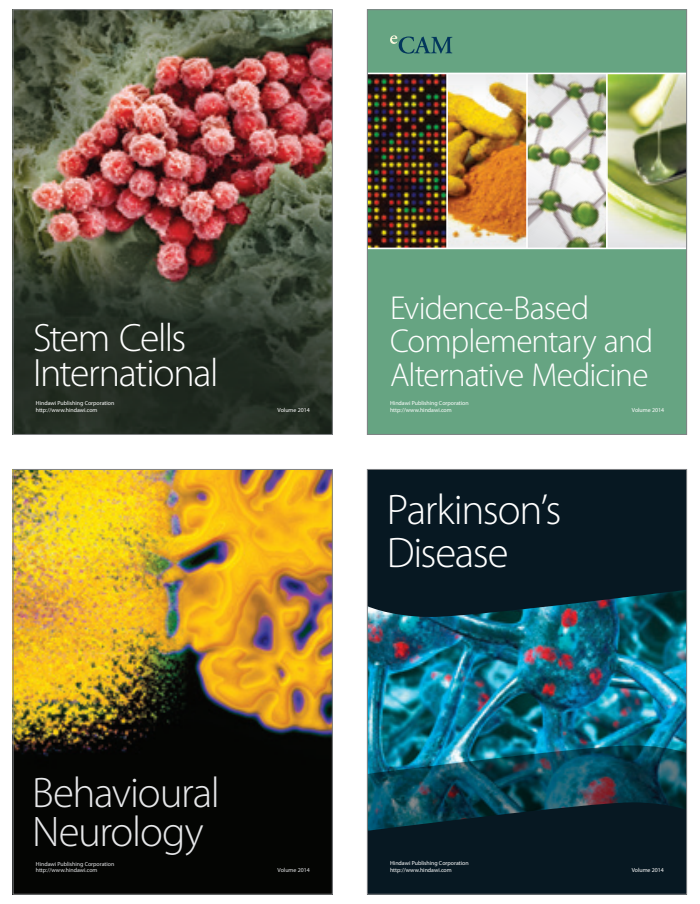
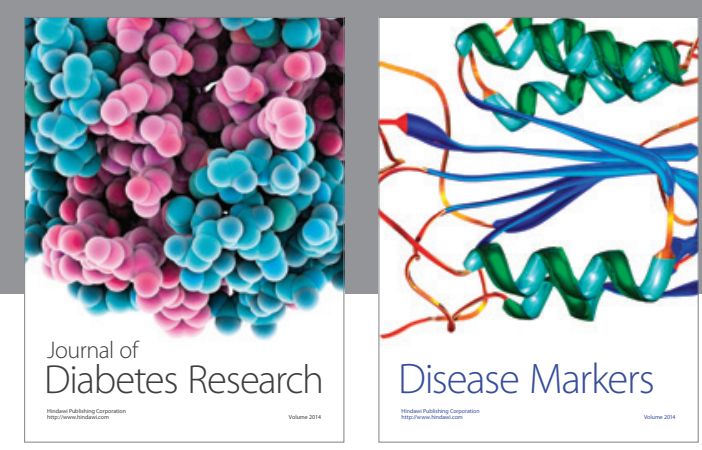

Disease Markers
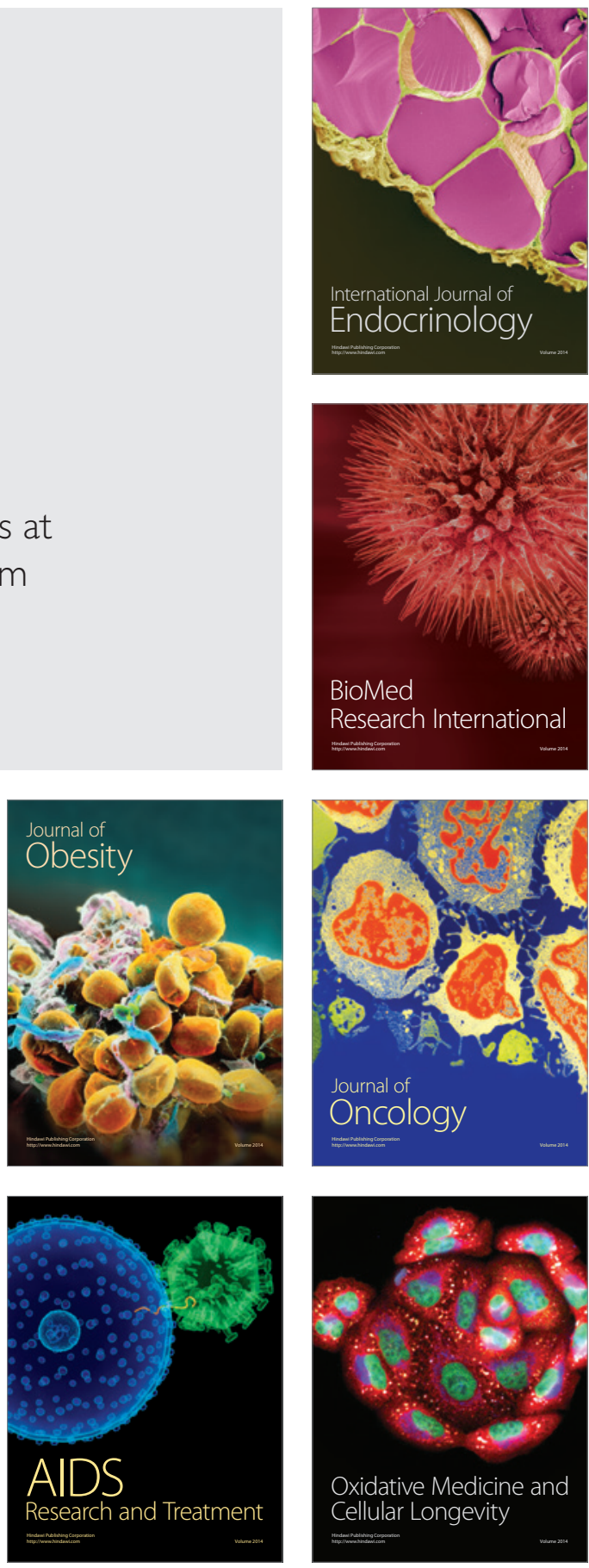